\title{
Using Observed Signals from the Arctic Stratosphere and Indian Ocean to Predict April-May Precipitation in Central China
}

\author{
Fei XIE AND XuAn MA \\ College of Global Change and Earth System Science, Beijing Normal University, Beijing, China \\ JIANPING LI \\ Key Laboratory of Physical Oceanography/Institute for Advanced Ocean Studies, Ocean University of China and Qingdao \\ National Laboratory for Marine Science and Technology, Qingdao, China \\ WENSHOU TIAN \\ College of Atmospheric Sciences, Lanzhou University, Lanzhou, China \\ CHENGQING RUAN \\ North China Sea Marine Forecasting Center of State Oceanic Administration, Qingdao, China \\ CHENG SUN \\ College of Global Change and Earth System Science, Beijing Normal University, Beijing, China
}

(Manuscript received 8 August 2018, in final form 16 July 2019)

\begin{abstract}
A linear regression model is constructed to predict the April-May precipitation in central China (PCC) with a lead time of 1-2 months. This model not only reproduces the historical April-May PCC from 1985 to 2006 but also demonstrates strong robustness and reliability during the independent test period of 2007-16. Two preceding factors are selected to build the model, the February-March Arctic stratospheric ozone (ASO) and Indian Ocean sea surface temperature $\left(\mathrm{IO}_{\mathrm{SST}}\right)$, indicating a synergistic impact of Arctic and tropical signals on the midlatitude climate. A possible mechanism of ASO changes affecting Chinese precipitation is that the stratospheric circulation anomalies related to ASO changes may downward influence circulation over North Pacific, and then extend westward to influence East Asia, leading to changes in Chinese precipitation. Anomalies of the other predictor, $\mathrm{IO}_{\mathrm{SST}}$, are associated with a baroclinic structure over central China. For example, warm $\mathrm{IO}_{\mathrm{SST}}$ causes anomalous convection over central China and affects the warm and humid airstream flowing from the Pacific to China. These processes related to the two predictors result in the April-May PCC anomalies. Sensitivity experiments and a transient experiment covering a longer period than the observations/reanalysis support the results from our statistical analysis based on observations. It implies that this statistical model could be applied to the output of seasonal forecasts from observations and improve the forecasting ability of April-May PCC in the future.
\end{abstract}

\section{Introduction}

Located in East Asia and characterized by complex topography, China has a major agricultural sector. Its climate, especially its precipitation, has received extensive attention due to the critical impact on

Corresponding author: Dr. Xuan Ma, maxuan@mail.bnu.edu.cn agricultural and economic productivity (e.g., Lau and $\mathrm{Li}$ 1984; Ding 1994; Gong and Wang 2000; Manton et al. 2001; Gong and Ho 2002; Huang et al. 2003; Wang et al. 2003; Gemmer et al. 2004; Li et al. 2015). However, most previous studies explored the changes and predictability of summer precipitation in China (e.g., Chang et al. 2000; Xie et al. 2009) but paid less attention to spring precipitation, which is much lower. In fact, spring 
precipitation is very important for the natural environment. For example, spring precipitation affects the sowing and growth of crops and the formation and development of sandstorms in China. Greater spring rainfall results in nearly saturated soil moisture and higher water levels in rivers and reservoirs, which can lead to flooding in the subsequent summer. Moreover, the interdecadal and interannual variations of spring precipitation are very different from those of summer precipitation (Chen et al. 2009). The changes and predictability of spring precipitation in China deserve more attention.

The factors and mechanisms affecting spring precipitation in China have already been investigated in prior work (e.g., Yang and Lau 2004; Xin et al. 2006; Qiu et al. 2009; Feng and Li 2011; Chen et al. 2014; Feng et al. 2014). Some studies reported a close relation between El Niño-Southern Oscillation (ENSO) and spring precipitation in southern China (Zhang et al. 1999; Wang et al. 2000; Zhang and Sumi 2002; Wu et al. 2003; Feng and Li 2011; Sun and Yang 2012). Wang et al. (2000) pointed out that the sea surface temperature (SST) changes associated with El Niño can facilitate the development of a lower-tropospheric anticyclone located in the western North Pacific. The anomalous anticyclone may act as a link between El Niño and East Asian climate, increasing the spring precipitation over southern China because of enhanced southerly winds on its northwest flank. Feng and Li (2011) found that different types of El Niño have different effects on spring precipitation over south China; that is, El Niño Modoki is accompanied by reduced rainfall, whereas the canonical El Niño is characterized by enhanced rainfall. The Indian Ocean can also have an important effect on spring precipitation in China (Xie et al. 2009; Chen et al. 2014; Feng et al. 2014). Feng et al. (2014) demonstrated that the south Indian Ocean subtropical dipole (IOSD) can affect spring rainfall over central-eastern China by modulating the meridional circulation. Xie et al. (2009) suggested that the tropical Indian Ocean could influence spring precipitation in China through maintaining the Philippine Sea anticyclone. Other studies found that Eurasian-Tibetan Plateau snow cover has contributed greatly to spring precipitation changes in China. For example, Wu and Kirtman (2007) suggested that the spring snow cover over western Siberia and the Tibetan Plateau is positively correlated with spring rainfall in southern China. Zuo et al. (2012) showed that a decrease of snow cover in Eurasia reduces spring rainfall over southeastern and northeastern China but increases it over southwestern and northwestern China. In addition, other factors responsible for the variations of spring precipitation in China have also been identified, including the thermal conditions (Liu and Wang 2011; Sun and Yang 2012), the monsoon
(Wang et al. 2002; Zhu et al. 2011), and the North Atlantic Oscillation (Sun and Yang 2012).

Previously, Zuo et al. (2012) pointed out that the maximum relative variability of spring precipitation in China occurs in central China from the Yangtze River basin to North China, which is an important grainproducing region with a large population. Therefore, a reliable projection of spring precipitation in central China would be very useful. Recently, Xie et al. (2018) found that April-May precipitation in central China (PCC) is closely related to February-March Arctic stratospheric ozone (ASO) variations. They reported that the circulation anomalies over the North Pacific related to February-March ASO changes may extend westward to central China, leading to the April-May PCC anomalies. Given that most previous studies used the circulation fields directly as predictors to establish the model for predicting local precipitation, a question arises: Can the atmospheric chemical composition, ASO, which is known to be associated with Northern Hemisphere circulation and surface climate change (Folland et al. 1990; Hurrell 1996; Jones et al. 1999; Smith and Polvani 2014; Calvo et al. 2015; Xie et al. 2016, 2017a,b; Ivy et al. 2017), be used as a predictor for April-May PCC?

In this paper, we use the observed February-March ASO combined with observed SST over the Indian Ocean to build a linear regression model for prediction of April-May PCC. The remainder of the paper is organized as follows. Section 2 introduces the data, methods, and simulations used in this study. Section 3 selects the factors and reveals the mechanism. Section 4 establishes the linear regression model for April-May PCC and validates the model based on observations and simulations. Finally, the results and conclusions are given in section 5 .

\section{Data, method, and simulations}

\section{a. Data}

Three sets of monthly precipitation are employed in this study. The rainfall from the National Meteorological Information Center of the China Meteorological Administration (CMA), which is based on the precipitation data of 2472 Chinese stations on the basis of the latest compilation of the National Meteorological Information Center and uses a thin plate spline method for spatial interpolation to generate the grid data with a horizontal resolution of $0.5^{\circ} \times 0.5^{\circ}$. The following two datasets are mainly utilized for comparison. One is from the Global Precipitation Climatology Project (GPCP) monthly precipitation dataset provided by the NOAA/OAR/ESRL PSD, Boulder, Colorado, from their website at https:// www.esrl.noaa.gov/psd/, combining observations and satellite precipitation data into $2.5^{\circ} \times 2.5^{\circ}$ global grids 
(a)

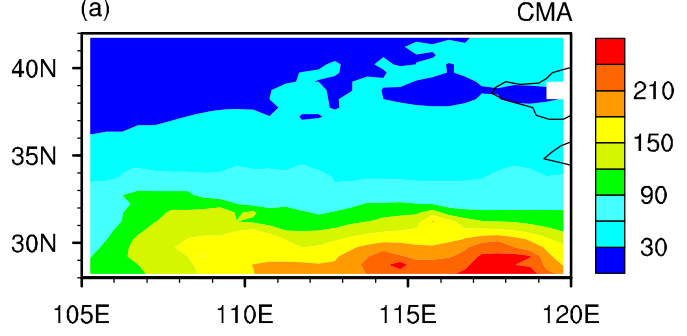

(c)

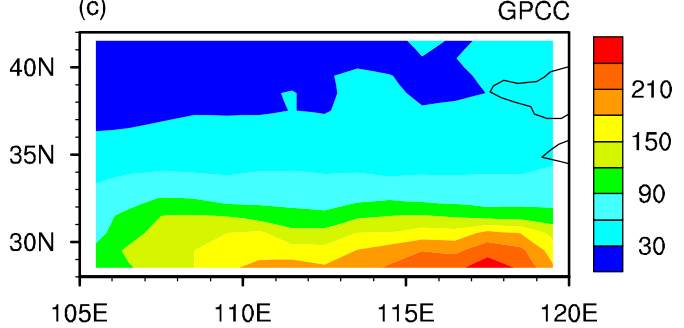

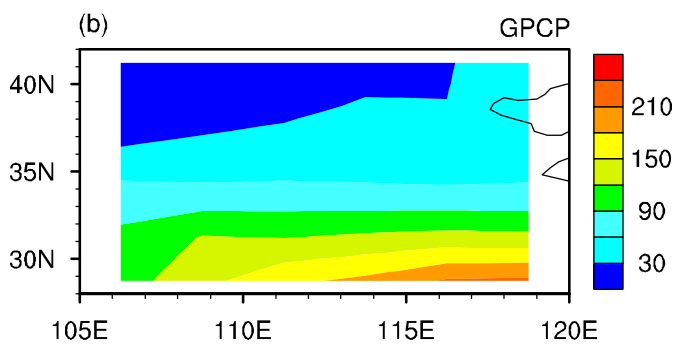

(d)

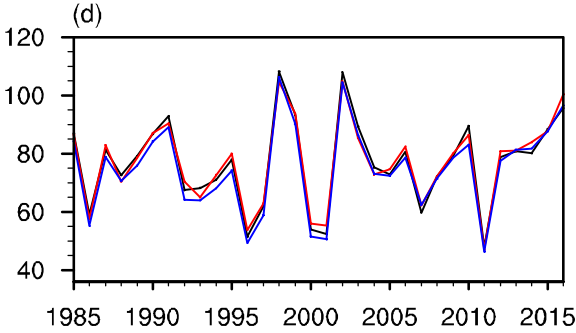

FIG. 1. Climatologies of April-May precipitation $\left(\mathrm{mm}\right.$ month $\left.{ }^{-1}\right)$ over central China $\left(28^{\circ}-42^{\circ} \mathrm{N}, 105^{\circ}-120^{\circ} \mathrm{E}\right)$ for the period 1985-2016 from the (a) CMA, (b) GPCP, and (c) GPCC. (d) Time series (1985-2016) of April-May precipitation $\left(\mathrm{mm} \mathrm{month}{ }^{-1}\right.$ ) over central China (PCC) averaged over the region $28^{\circ}-42^{\circ} \mathrm{N}, 105^{\circ}-120^{\circ} \mathrm{E}$. The black, red, and blue lines represent the precipitation from CMA, GPCP, and GPCC, respectively.

(Adler et al.2003). The other is from Global Precipitation Climatology Centre (GPCC) based on the monitoring product and Full Data Product V7 on the basis of qualitycontrolled data on a regular grid with a spatial resolution of $1.0^{\circ} \times 1.0^{\circ}$ (Schneider et al. 2008).

According to the relationship between ASO and PCC in Xie et al. (2018), central China is defined as the region $28^{\circ}-42^{\circ} \mathrm{N}, 105^{\circ}-120^{\circ} \mathrm{E}$ in this study. Time series $(1985-$ 2016) of April-May precipitation (mm month ${ }^{-1}$ ) over central China (PCC) averaged over the region $28^{\circ}-42^{\circ} \mathrm{N}$, $105^{\circ}-120^{\circ} \mathrm{E}$ are used in this study. To ensure the reliability of April-May precipitation data and understand its characteristics, Figs. 1a-c show the climatology of April-May precipitation from three precipitation datasets, illustrating that the precipitation in April-May is decreasing from south to the north in central China. Figure 1d presents the April-May PCC time series, showing significant interannual variations. Figure 1 illustrates that all three datasets of precipitation show a high degree of consistency.

The ASO index is defined as the monthly mean partial ozone column averaged for the latitude range of $60^{\circ}-90^{\circ} \mathrm{N}$ at an altitude of 100-50 hPa after removing the linear trend and seasonal cycle. The ozone profiles for the period 1985-2016 (there are many missing values on these layers from 100 to $50 \mathrm{hPa}$ of the ozone data in 1984, so we start this study in 1985) are taken from the Stratospheric Water and Ozone Satellite Homogenized (SWOOSH) dataset, which is a merged record of stratospheric ozone and water vapor measurements taken by a number of limb sounding and solar occultation satellites (Davis et al.
2016). The SWOOSH record is comprised of data from the SAGE-II/III, UARS HALOE, UARS MLS, and Aura MLS instruments and consists of monthly mean zonalmean values with a resolution of $2.5^{\circ} \times 2.5^{\circ}$ and 31 vertical levels (316-1 hPa). Previous studies (Xie et al. 2016, 2018) show that it compares well with ozone data from the Global Ozone Chemistry and Related Trace Gas Data Records for the Stratosphere (GOZCARDS; 1985-2013) project (Froidevaux et al. 2015). Other monthly datasets for wind, geopotential height, vertical velocity, relative humidity, and air temperature are taken from the National Centers for Environmental Prediction-Department of Energy (NCEP-DOE) dataset. Sea surface temperature is derived from the Hadley Centre SST dataset with resolution of $1.0^{\circ} \times 1.0^{\circ}$ (HadISST; Rayner et al. 2003).

\section{b. Methodology}

Though local precipitation may be affected by nonlinear climate forcing factors, a linear model still performs well on the monthly mean seasonal time scale (Guo et al. 2012). Zorita and von Storch (1999) pointed out that a linear model can offer a clearer physical interpretation. Thus, multilinear regression is used to establish the model in this study. Once the linear regression model has been constructed, it is necessary to check its stability and predictability. Therefore, datasets of the predictand and potential forcing predictors are divided into two parts, the training period (19852006) for constructing the linear regression model and the test period (2007-16) for demonstrating its hindcast ability. 
TABLE 1. CESM-WACCM4 experiments with various specified ozone forcing. The integration time for time-slice runs is 33 years.

\begin{tabular}{|c|c|c|}
\hline Expt & Specified ozone forcing & Other forcing \\
\hline E1 & $\begin{array}{l}\text { Time-slice run as the control experiment used case } \\
\text { F_2000_WACCM_SC; specified ozone forcing is a } \\
\text { 12-month cycle of monthly ozone averaged from } \\
1995 \text { to } 2005\end{array}$ & $\begin{array}{l}\text { Fixed solar constant, fixed greenhouse gas (GHG) values } \\
\text { [averages of emissions scenario A2 of the Intergovernmental } \\
\text { Panel on Climate Change (WMO 2003) over the period } \\
\text { 1995-2005], volcanic aerosols (from the Stratospheric } \\
\text { Processes and their Role in Climate (SPARC) Chemistry- } \\
\text { Climate Model Validation (CCMVal) REF-B2 scenario } \\
\text { recommendations), and QBO phase signals with a 28-month } \\
\text { zonal wind fixed cycle }\end{array}$ \\
\hline E2 & $\begin{array}{l}\text { Same as E1, except that the February-March ozone in } \\
\text { the region } 60^{\circ}-90^{\circ} \mathrm{N} \text { at } 100-50 \mathrm{hPa} \text { is decreased by } \\
15 \% \text { compared with } \mathrm{E} 1\end{array}$ & Same as E1 \\
\hline E3 & $\begin{array}{l}\text { Same as E1, except that February-March ozone in the } \\
\text { region } 60^{\circ}-90^{\circ} \mathrm{N} \text { at } 100-50 \mathrm{hPa} \text { is increased by } 15 \% \\
\text { compared with E1 }\end{array}$ & Same as E1 \\
\hline
\end{tabular}

We calculate the anomaly sign consistency $P$ to compare the observed and fitted PCCs using the following equation:

$$
P=\frac{N^{c}}{N}
$$

where $N^{c}$ represents the number of cases when the observed and fitted PCCs both have either positive or negative anomalies at the same time and $N$ represents the sample size.

\section{c. Simulations}

The National Center for Atmospheric Research's Community Earth System Model (CESM), version 1.0.6, has been employed in this study. CESM is a fully coupled global climate model that incorporates interactive atmospheric (CAM/WACCM), ocean (POP2), land (CLM4), and sea ice (CICE) components. For the atmospheric component, we used the Whole Atmosphere (a)

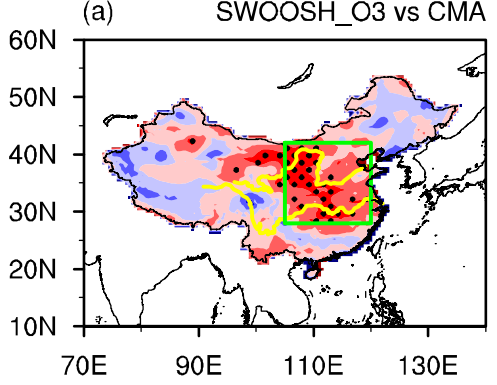

(d)

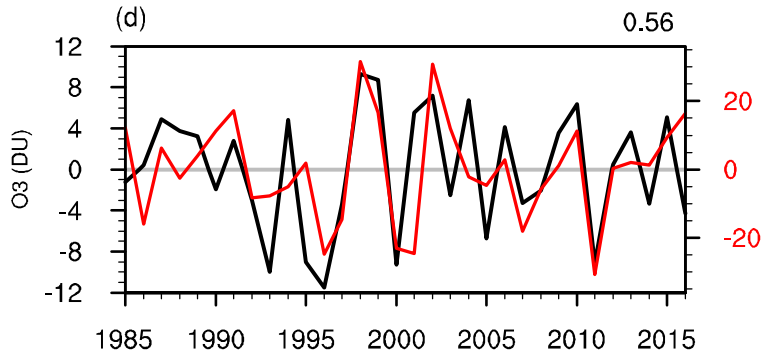

(b) SWOOSH O3 vs GPCC

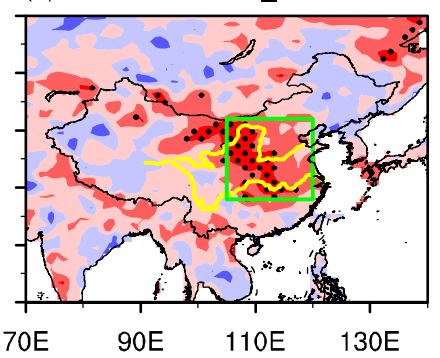

(c)

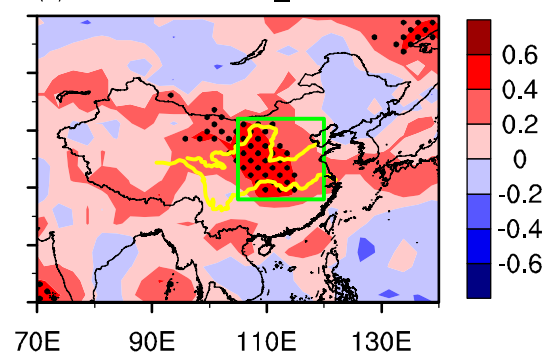

(e)

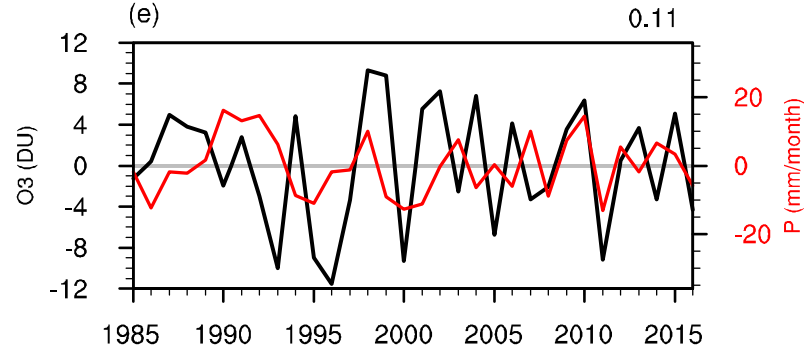

FIG. 2. (a)-(c) Correlation coefficients between the February-March mean ASO index and the April-May mean precipitation anomalies for the period 1985-2016. The ASO index is from SWOOSH, and precipitation is from the (a) CMA, (b) GPCC, and (c) GPCP. Dots in (a)-(c) indicate that correlations are significant at the $95 \%$ confidence level. The seasonal cycle and linear trend have been removed from the original datasets before calculating correlation coefficients. The yellow lines represent the Yangtze River and the Yellow River. (d) Time series of February-March mean ASO index (black line) and April-May mean precipitation (red line) anomalies averaged over the region $28^{\circ}-42^{\circ} \mathrm{N}, 105^{\circ}-120^{\circ} \mathrm{E}$ from CMA. (e) As in (d), but for February-March mean ASO index and precipitation. The correlation coefficient between the two time series is given in the upper-right corner of each panel. The seasonal cycle and linear trend have been removed in (d) and (e). The green square in (a)-(c) denotes the area studied (central China). 
(a)

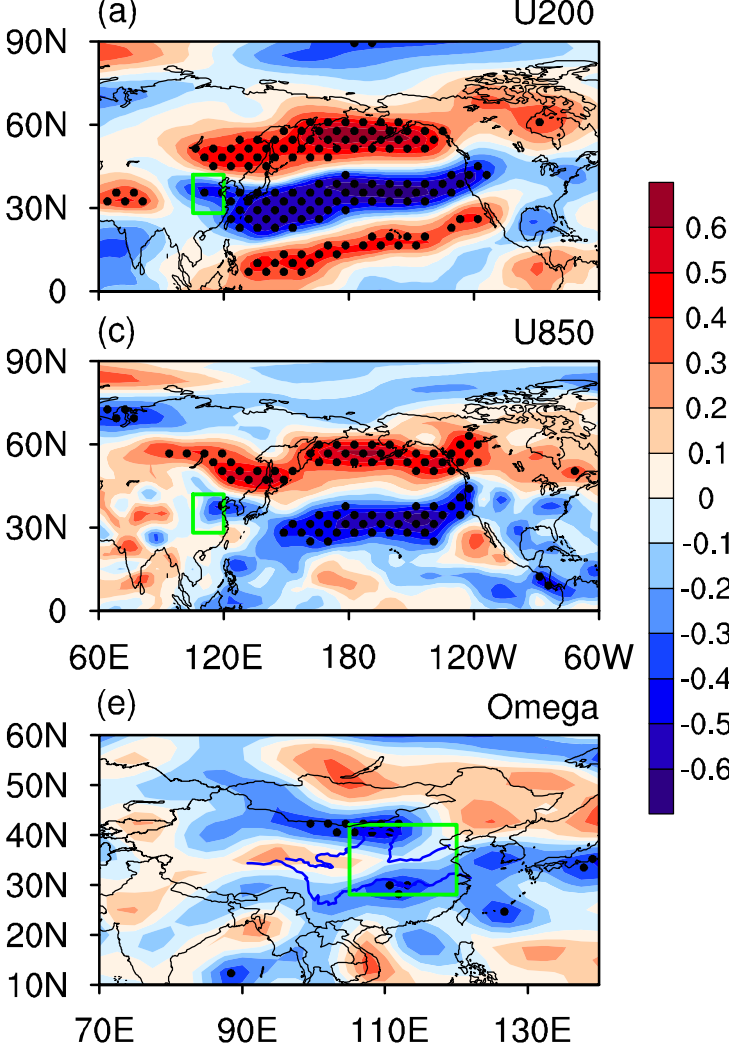

(b)

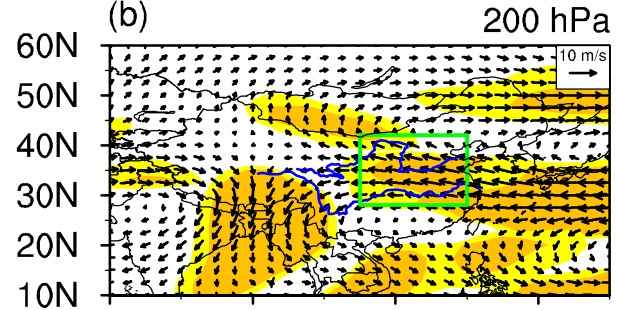

(d)

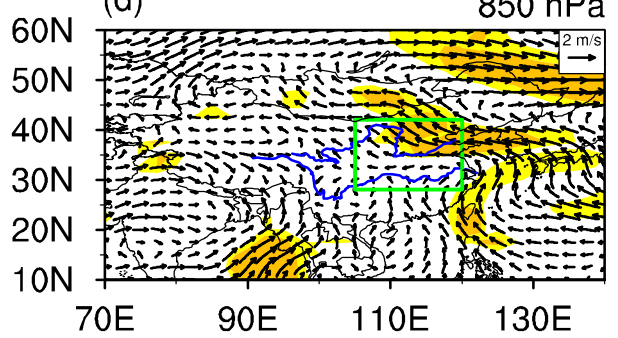

(f)

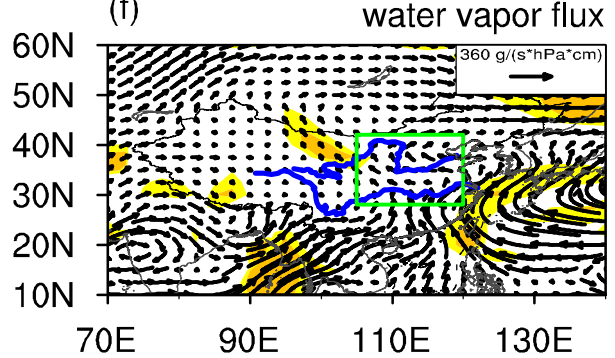

FIG. 3. (left) Correlation coefficients between February-March mean ASO index and April-May mean zonal wind $\left(\mathrm{m} \mathrm{s}^{-1}\right.$ ) at (a) $200 \mathrm{hPa}$ and (c) $850 \mathrm{hPa}$ and (e) vertical velocity $\left(\mathrm{Pa} \mathrm{s}^{-1}\right)$ at $500 \mathrm{hPa}$ for 1985-2016. Dots indicate areas that are statistically significant at the $95 \%$ confidence level. (right) Differences in composite April-May horizontal wind ( $\mathrm{m} \mathrm{s}^{-1}$ ) at (b) $200 \mathrm{hPa}$ and (d) $850 \mathrm{hPa}$ and (f) composite April-May vertically integrated water vapor flux $\left.\left[\mathrm{g}(\mathrm{s} \mathrm{hPa} \mathrm{cm})^{-1}\right)\right]$ between positive and negative events of the February-March ASO anomaly from 1985 to 2016. Colored regions are statistically significant at the $90 \%$ (light yellow) and $95 \%$ (dark yellow) confidence levels. The ASO anomaly events are selected based on Table 2. The seasonal cycle and linear trend have been removed from the original datasets before calculating correlation coefficients and the composite analysis. ASO is from SWOOSH. Wind is from NCEP2. The green square denotes the area studied (central China).

Community Climate Model (WACCM), version 4 (Marsh et al. 2013). WACCM4 is a climate model with detailed middle-atmosphere chemistry and a finitevolume dynamical core, and it extends from the surface to $\sim 140 \mathrm{~km}$ with 66 vertical levels. For our study, we disabled the interactive chemistry. Our simulations used a horizontal resolution of $1.9^{\circ} \times 2.5^{\circ}$ (latitude $\times$ longitude) for the atmosphere, and approximately the same for the ocean.

Three time slice experiments (E1-E3) are used in this paper. Details of these experiments are given in Table 1. All the experiments were all run for 33 years, with the first 3 years excluded for the model spinup and only the last 30 years used for our analysis.

A transient experiment (1955-2005) is performed using CESM with the fully coupled ocean incorporating both natural and anthropogenic external forcings, including spectrally resolved solar variability (Lean et al.
2005), transient greenhouse gases (GHGs) (from IPCC scenario A1B), volcanic aerosols [from the Stratospheric Processes and their Role in Climate (SPARC) ChemistryClimate Model Validation (CCMVal) REF-B2 scenario recommendations], a nudged quasi-biennial oscillation (QBO) (the time series in CESM is determined from the observed climatology over the period 1955-2005), and ozone forcing. Note that the specified ozone forcing from 1955-2005 is WACCM4 model produced ozone, derived from simulations that were prepared for the CMIP5 project. All the forcing data used in this study are available from the CESM model input data repository.

\section{Selecting the factors and analyzing the related mechanisms}

Figures 2a-c show gridpoint correlation coefficients between the February-March mean ASO index 
TABLE 2. Selected positive and negative years for February-March mean ASO anomaly events based on SWOOSH data for the period 1985-2016. Positive and negative February-March mean ASO anomaly events are defined using a normalized time series of February-March ASO variations from 1985 to 2016. Values larger than +1 standard deviation are defined as positive February-March ASO anomaly events, and those below -1 standard deviation are defined as negative February-March ASO anomaly events.

\begin{tabular}{ccc}
\hline \hline & Positive anomaly events & Negative anomaly events \\
\hline ASO & $1998,1999,2002,2004,2010$ & $1993,1995,1996,2000,2005,2011$ \\
\hline
\end{tabular}

and the April-May mean precipitation. They show that the February-March ASO is strongly positively correlated with April-May precipitation in central China. To further understand the relationship between February-March ASO and April-May precipitation in central China, the time series of the February-March mean ASO index and April-May precipitation anomalies averaged over the region $28^{\circ}-42^{\circ} \mathrm{N}, 105^{\circ}-120^{\circ} \mathrm{E}$ are presented in Fig. 2d. The correlation coefficient of the two time series is 0.56 , significant at the $95 \%$ confidence level. However, the simultaneous (FebruaryMarch) ASO changes and precipitation variations are not significantly related (Fig. 2e; $R=0.11$ ). This implies that the February-March mean ASO variations relate to April-May PCC with a lead time of 1-2 months. The

(a)

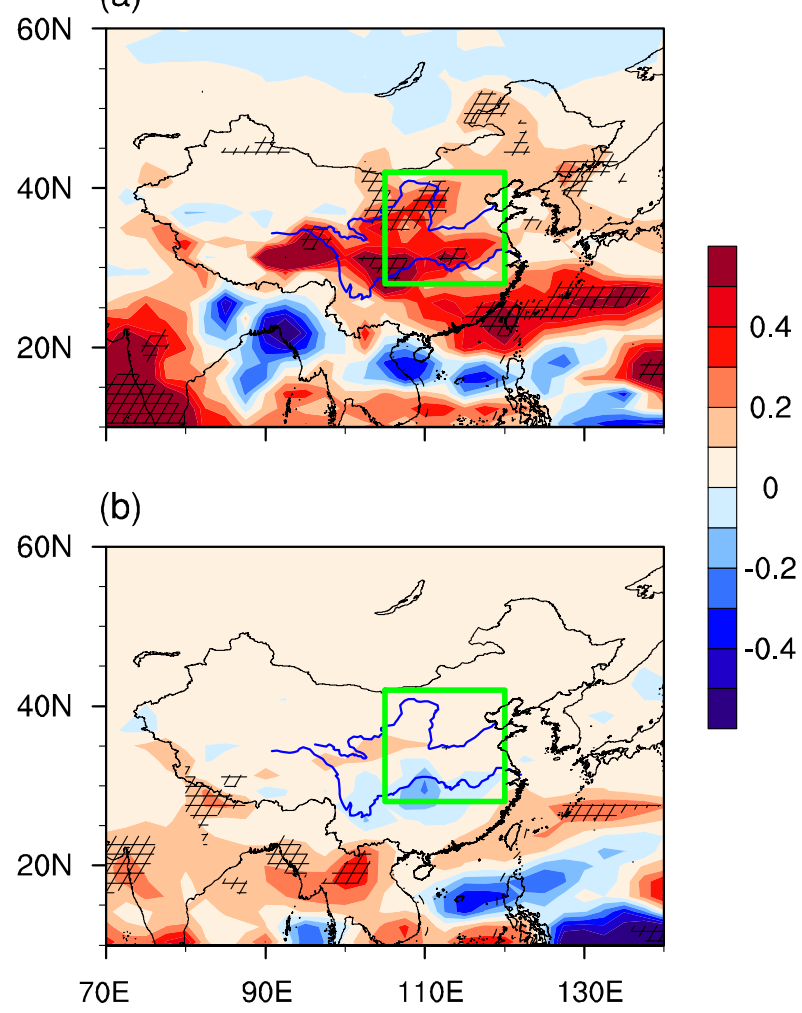

FIG. 4. The difference in (a) April-May mean and (b) FebruaryMarch mean precipitation $\left(\mathrm{mm} \mathrm{day}^{-1}\right.$ ) between experiments E3 and E2. Black hatched areas are significant at the $95 \%$ confidence level. The green square denotes the area studied (central China). relationship between ASO and precipitation is delayed by 1-2 months, perhaps because the stratospheric circulation anomalies related to ASO changes take 1-2 months to propagate to the Northern Hemispheric midlatitude surface (Smith and Polvani 2014; Calvo et al. 2015; Xie et al. 2016; Ivy et al. 2017). Based on this relationship between February-March ASO and April-May PCC, we select February-March ASO as the first predictor.

To identify the possible physical mechanisms that underlie this relationship between February-March ASO and April-May PCC, the lagged response of circulation variations to the ASO changes is shown in Fig. 3. Xie et al. (2017b) had explained a possible mechanism for how ASO influences the North Pacific and why ASO has a lagged impact on the circulation in the Northern Hemispheric mid- to high latitudes. They found that the stratospheric circulation anomalies related to ASO changes may rapidly extend to the lower troposphere in the Northern Hemisphere high latitudes; however, the lower-troposphere high-latitude circulation anomalies may take about 1 month to propagate to the North Pacific midlatitudes. The intensity of the circulation over North Pacific may be influenced by ASO changes and the areas of significant correlation are mainly located in the North Pacific with a zonal distribution, with positive correlations in the higher and lower latitudes of the North Pacific and negative correlations in the midlatitudes of the North Pacific when the ASO is anomalously high (Figs. 3a,c).

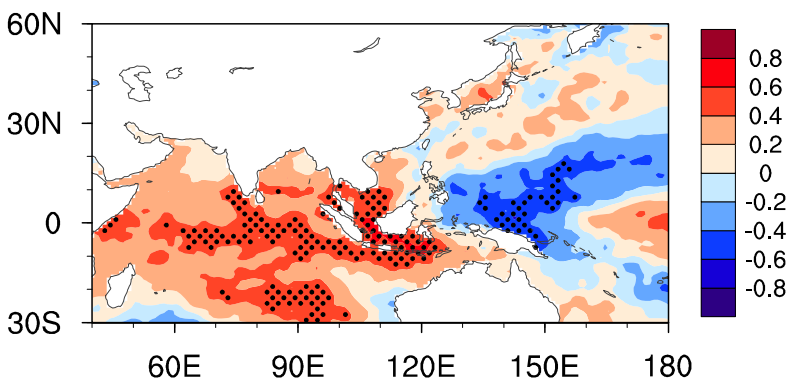

FIG. 5. Correlation coefficients between April-May PCC NO_AsO $_{\text {AsO }}$ and February-March SST anomalies during 1985-2016. Dots denote significance at the $95 \%$ confidence level, according to the Student's $t$ test. Precipitation and SST are from CMA and HadISST, respectively. 


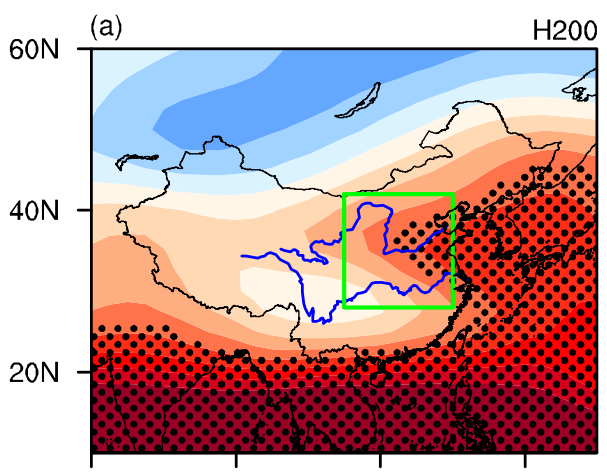

(c)
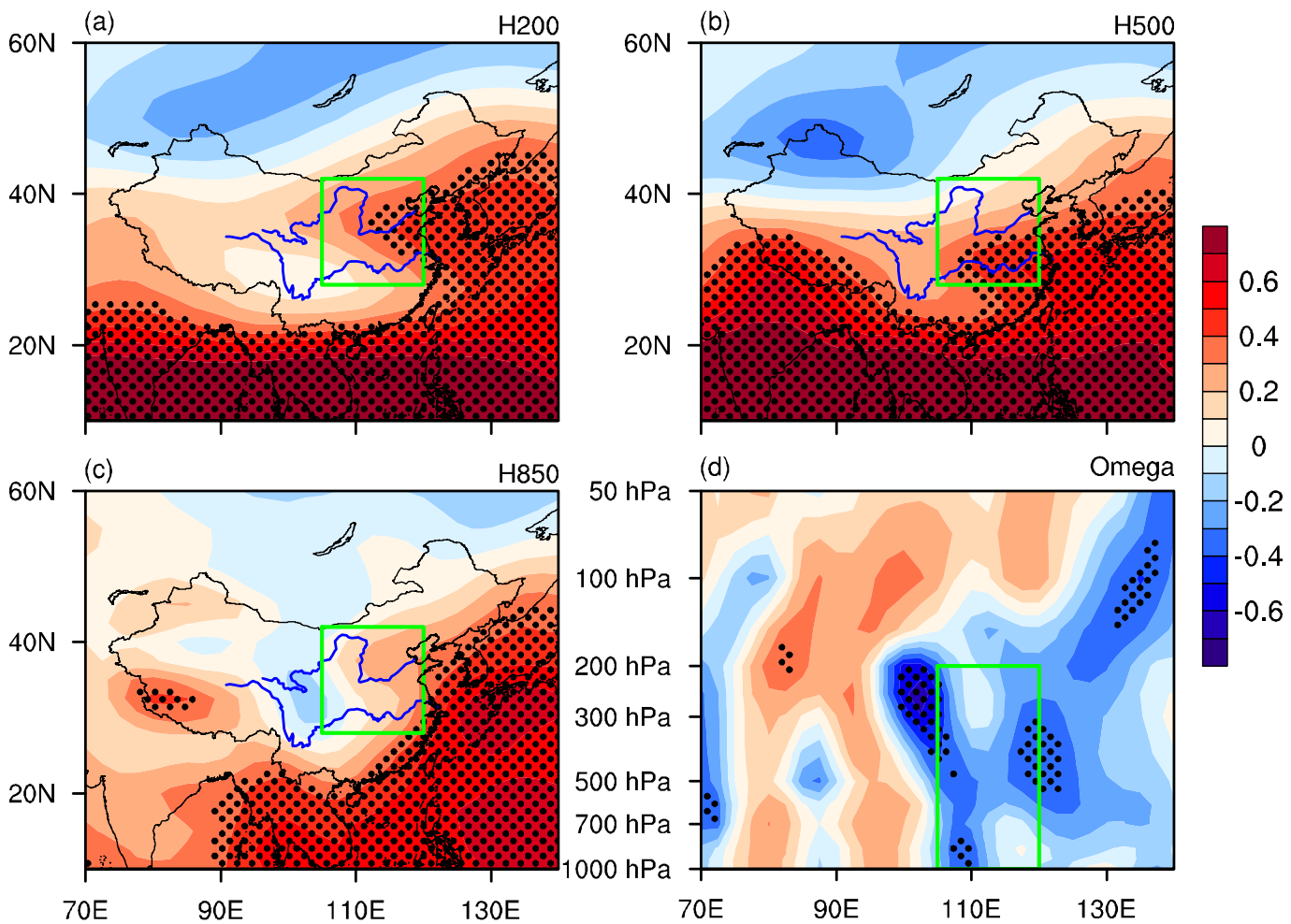

FIG. 6. Correlation coefficients between February-March IO $_{\text {SST }}$ variations and April-May geopotential height anomalies at (a) 200, (b) 500, and (c) $850 \mathrm{hPa}$ during the period 1985-2016. Before performing the analysis, the seasonal cycle and linear trend were removed from the original datasets. (d) Longitude-pressure plot of correlation coefficients between February-March $\mathrm{IO}_{\text {SST }}$ variations and April-May vertical velocity anomalies (averaged over $28^{\circ}-42^{\circ} \mathrm{N}$ ) during the period 1985-2016. Red (blue) colors represent descending (ascending) motion. Dots denote significance at the $95 \%$ confidence level, according to the Student's $t$ test. The green square denotes the area studied (central China).

These circulation anomalies may extend westward to East Asia, affecting the local circulation anomalies in central China. The wind changes in Figs. $3 \mathrm{~b}$ and $3 \mathrm{~d}$, corresponding to the zonal wind changes in Figs. $3 \mathrm{a}$ and $3 \mathrm{c}$, present a baroclinic structure with an abnormal anticyclone in the upper troposphere and an abnormal cyclone in the lower troposphere over central China during positive ASO anomaly events (see Table 2 for a list of positive and negative ASO anomaly events). This process enhances the warm and humid airstream from the western Pacific to the Chinese mainland (Fig. 3f) and strengthens the upwelling over central China (Fig. 3e), leading to more precipitation in central China, and vice versa for a decrease in ASO.

In addition, we further perform time-slice experiments to investigate the relationship between ASO and PCC. The result is shown in Fig. 4. It shows that only the February-March ASO increase would be enough to force a statistically significant increase in April-May PCC (Fig. 4a) but have no significant impact on February-March PCC (Fig. 4b), consistent with the observations. More details of physical mechanisms by which February-March ASO affects April-May PCC can be found in Xie et al. (2018).

The following equation first establishes the relationship between February-March ASO and April-May PCC by linear regression:

$$
\mathrm{PCC}_{\mathrm{ASO}}=73.87+1.33 \mathrm{ASO},
$$

where $\mathrm{PCC}_{\mathrm{ASO}}$ is the time series of April-May PCC variations associated with February-March ASO. The units of $\mathrm{PCC}_{\mathrm{ASO}}$ and $\mathrm{ASO}$ are millimeters $(\mathrm{mm})$ and Dobson units (DU), respectively. The units of the constants 73.87 and 1.33 are $\mathrm{mm}$ and $\mathrm{mm} \mathrm{DU}^{-1}$, respectively.

Then, removing the ASO signal from the PCC, we have

$$
\begin{aligned}
\mathrm{PCC}_{\mathrm{NO} \_\mathrm{ASO}} & =\mathrm{PCC}-\mathrm{PCC}_{\mathrm{ASO}} \\
& =\mathrm{PCC}-73.87-1.33 \mathrm{ASO},
\end{aligned}
$$

where $\mathrm{PCC}_{\mathrm{NO}}$ Aso is the part of April-May PCC that is independent of February-March ASO. The units of $\mathrm{PCC}_{\mathrm{NO}}$ ASO are $\mathrm{mm}$. 
(a)

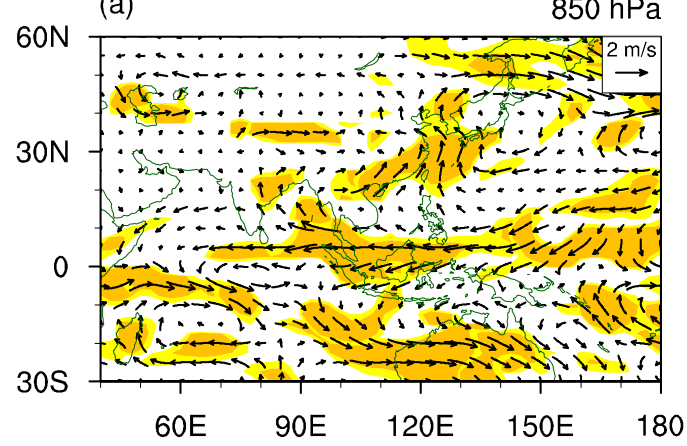

(b)

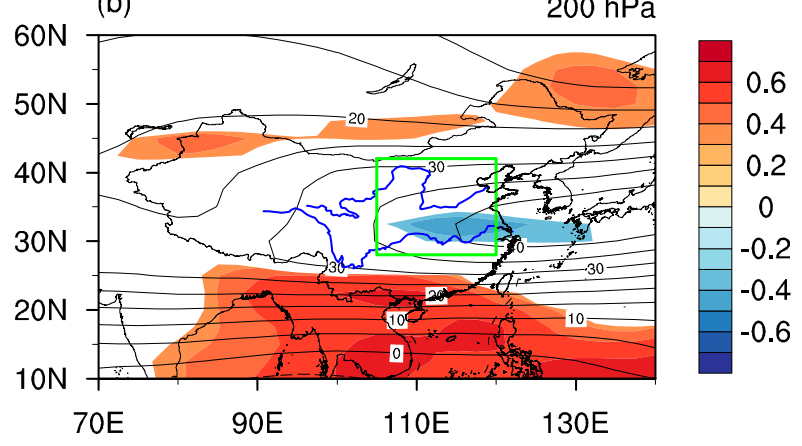

(c)

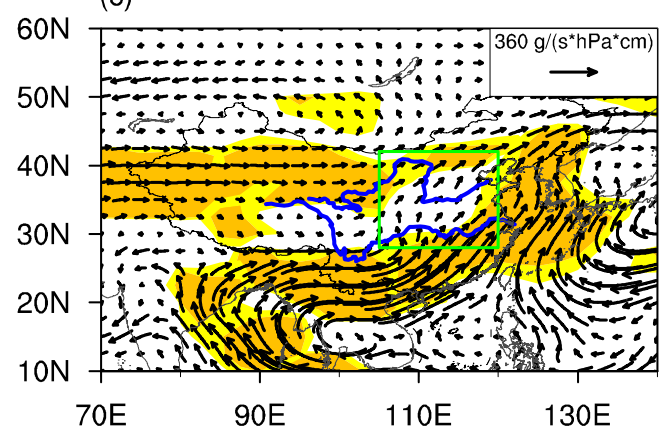

FIG. 7. (a) Differences in composite April-May wind (vectors; $\mathrm{m} \mathrm{s}^{-1}$ ) between positive and negative February-March $\mathrm{IO}_{\mathrm{SST}}$ anomaly events at $850 \mathrm{hPa}$ for 1985-2016. Colored regions are statistically significant at the $90 \%$ (light yellow) and $95 \%$ (dark yellow) confidence levels. (b) Correlation coefficients (colors) between February-March $\mathrm{IO}_{\text {SST }}$ and April-May zonal wind $\left(\mathrm{m} \mathrm{s}^{-1}\right)$ at $200 \mathrm{hPa}$ for 1985-2016. Only regions with statistical significance above the $95 \%$ confidence level are colored. Black solid lines represent the climatology of the April-May zonal wind. (c) Differences in composite April-May vertically integrated water vapor flux [vectors; $\mathrm{g}(\mathrm{s} \mathrm{hPa} \mathrm{cm})^{-1}$ ] between positive and negative February-March $\mathrm{IO}_{\mathrm{SST}}$ anomaly events for 1985-2016. Colored regions are statistically significant at the $90 \%$ (light yellow) and 95\% (dark yellow) confidence levels. The February-

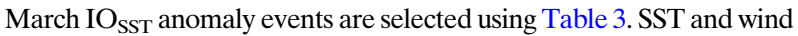
are from HadISST and NCEP2, respectively. The green square denotes the area studied (central China).

The next step is to find another predictor for the remaining precipitation ( $\mathrm{PCC}_{\mathrm{NO} \_\mathrm{AsO}}$ ) that is not explained by the ASO. The Indian Ocean SST is the most frequently discussed of the factors known to affect spring precipitation in central China (Xie et al. 2009; Chen et al. 2014; Feng et al. 2014). Figure 5 shows the correlation coefficients between April-May $\mathrm{PCC}_{\mathrm{NO} \_\mathrm{ASO}}$ and February-March SST anomalies. The FebruaryMarch Indian Ocean sea surface temperature $\left(\mathrm{IO}_{\mathrm{SST}}\right)$ variations over the region $20^{\circ} \mathrm{S}-20^{\circ} \mathrm{N}, 40^{\circ}-105^{\circ} \mathrm{E}$ are indeed significantly correlated with April-May PCC $_{\text {NO_AsO. }}$ Therefore, February-March IO $_{\text {SST }}$ averaged over the region $20^{\circ} \mathrm{S}-20^{\circ} \mathrm{N}, 40^{\circ}-105^{\circ} \mathrm{E}$ is selected as the second factor to construct the model. We now investigate the physical processes linking February-March $\mathrm{IO}_{\text {SST }}$ and April-May PCC.

The correlation coefficients between FebruaryMarch $\mathrm{IO}_{\mathrm{SST}}$ variations and April-May geopotential height anomalies at 200, 500, and $850 \mathrm{hPa}$ are shown in Figs. 6a-c. There are positive geopotential height anomalies (anticyclonic) in the middle and upper troposphere over central China (Figs. 6a and 6b). In addition, there is a negative anomaly (cyclonic) at $850 \mathrm{hPa}$ over the western side of the Yangtze River and Yellow River region (Fig. 6c). Corresponding to the positive anomalies (anticyclonic) at middle and upper troposphere, the convergence of the airflow at lower level and divergence at high levels may lead to upwelling in central China. A longitude-pressure cross section of correlation coefficients between February-March IO $_{\text {SST }}$ variations and April-May vertical velocity anomalies (averaged over $28^{\circ}-42^{\circ} \mathrm{N}$ ) is shown in Fig. $6 \mathrm{~d}$. An anomalous rising airflow occurs over central China during the anomalously high $\mathrm{IO}_{\mathrm{SST}}$ events, corresponding to enhanced convective activity. This situation favors increased local precipitation, whereas anomalously low $\mathrm{IO}_{\text {SST }}$ events have the opposite effect.

Figure 7a shows differences in composite April-May wind between positive and negative February-March $\mathrm{IO}_{\text {SST }}$ anomaly events (see Table 3 for a list of positive and negative IO $_{\text {SST }}$ anomaly events). The warm IO $_{\text {SST }}$ can strengthen the anticyclone at $850 \mathrm{hPa}$ over Northeast Asia. This agrees with a previous study (Liu and Duan 2017) that reported that a warm Indian Ocean can cause an anomalous anticyclone over Northeast Asia that is closely related to anomalies in the western North Pacific subtropical high. This could transport a warm and humid southerly airflow to central-eastern China, increasing the water content in the local air. Figure $7 \mathrm{~b}$ shows the correlation coefficients between FebruaryMarch IO $_{\text {SST }}$ and April-May zonal wind variations at $200 \mathrm{hPa}$ (colored) and the climatology of the AprilMay zonal wind (black solid lines). The climatological jet stream at the upper level is located at around $30^{\circ} \mathrm{N}$. The $\mathrm{IO}_{\text {SST }}$ variations are anticorrelated (correlated) with zonal wind anomalies at $30^{\circ} \mathrm{N}\left(50^{\circ} \mathrm{N}\right)$, implying that $\mathrm{IO}_{\text {SST }}$ positive anomalies shift the upper-level jet 
TABLE 3. Positive and negative February-March $\mathrm{IO}_{\mathrm{SST}}$ anomaly events during 1985-2016. Values larger than +0.5 standard deviation are defined as positive February-March $\mathrm{IO}_{\mathrm{SST}}$ anomaly events, and those below -0.5 standard deviation are defined as negative February-March $\mathrm{IO}_{\mathrm{SST}}$ anomaly events.

\begin{tabular}{lcc}
\hline & Positive anomaly events & Negative anomaly events \\
\hline IO $_{\text {SST }}$ & $1987,1988,1990,1998,2003,2010,2016$ & $1985,1986,1989,1993,1994,1997,2000,2001,2006,2008,2011,2012$ \\
\hline
\end{tabular}

stream northward. Central China is then situated right at the entrance region of the jet. Both the anomalous anticyclone over Northeast Asia and the northward shift of the upper-level jet stream can influence central China. The differences in the water vapor flux anomalies associated with positive and negative anomalies of the February-March $\mathrm{IO}_{\mathrm{SST}}$ are presented in Fig. 7c. The warm and humid airstream from the South China Sea to China is indeed enhanced when the IO $_{\text {SST }}$ is abnormally high. In light of Figs. 6 and 7, the increased (decreased) water vapor concentration in the atmosphere and enhanced (reduced) upwelling over central China result in more (less) precipitation over central China during positive (negative) $\mathrm{IO}_{\mathrm{SST}}$ anomaly events.

Although the above analysis illustrates a significant correlation between $\mathrm{IO}_{\mathrm{SST}}$ anomalies and PCC variations, it is not clear how the February-March $\mathrm{IO}_{\mathrm{SST}^{-}}$ related atmospheric signal can persist to April-May to influence PCC. In fact, previous studies have investigated the simultaneous effect of $\mathrm{IO}_{\mathrm{SST}}$ on spring precipitation in central China (Xie et al. 2009; Chen et al. 2014; Feng et al. 2014). A possible reason for the significant correlation between February-March IO $_{\text {SST }}$ variations and April-May PCC (Figs. 5-7) is that the February-March IO $_{\text {SST }}$ anomalies can persist to AprilMay (Fig. 8), and then the April-May $\mathrm{IO}_{\mathrm{SST}}$ anomalies influence April-May PCC and circulation anomalies. The relationships among April-May $\mathrm{IO}_{\mathrm{SST}}$ anomalies and April-May PCC and circulation anomalies are in good agreement with the results from Figs. 5-7 (not shown). Since we want to build a statistical model with forecasting capability, it is more appropriate to use February-March $\mathrm{IO}_{\text {SST }}$ instead of April-May $\mathrm{IO}_{\mathrm{SST}}$ as a predictor in this study.

\section{Building the linear regression model for April-May PCC}

\section{a. Building the linear regression model based on observations}

The analysis in the previous section indicates that the signals from the Arctic and tropics can synergistically affect the midlatitude climate. The mechanisms by which the two selected predictors affect April-May PCC have also been discussed above. Figure 9a presents the standardized time series of February-March ASO and $\mathrm{IO}_{\text {SST }}$ variations. Note that the two factors display obvious interannual variations and are independent of each other $(R=0.14)$. This illustrates that selecting February-March ASO and $\mathrm{IO}_{\mathrm{SST}}$ to establish the linear regression model for predicting the April-May PCC is feasible.

The linear regression model takes the following form:

$$
\mathrm{PCC}=-570.63+1.14 \mathrm{ASO}+22.83 \mathrm{IO}_{\mathrm{SST}},
$$

where the units of April-May PCC, February-March ASO, and February-March $\mathrm{IO}_{\mathrm{SST}}$ are $\mathrm{mm}, \mathrm{DU}$, and ${ }^{\circ} \mathrm{C}$, respectively. The units of constants $-570.63,1.14$, and 22.83 are $\mathrm{mm}, \mathrm{mm} \mathrm{DU}^{-1}$, and $\mathrm{mm}^{\circ} \mathrm{C}^{-1}$, respectively.

The observed and fitted PCC variations are shown in Fig. 9b. The linear regression model performs well in estimating the precipitation. More details are provided in Table 4. During the training period from 1985 to 2006, the correlation coefficients, RMSE of cross-validation and anomaly sign consistency rate are $0.64,13.96 \mathrm{~mm}$, and $68 \%$, respectively. Note that the correlation coefficients are significant at the $95 \%$ confidence level and the anomaly sign consistency exceeds $60 \%$. During the independent test period (2007-16), the values are $0.80,15.80 \mathrm{~mm}$, and $80 \%$, respectively, similar to those for the training period (Table 4). The linear regression models in Figs. 9c and 9d are based on different training and test periods following Kim et al. (2004).

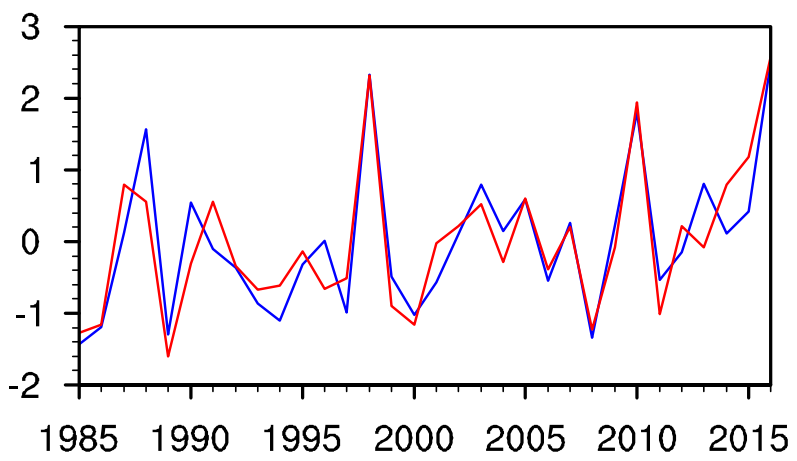

FIG. 8. Standardized time series of February-March (blue line) and April-May (red line) $\mathrm{IO}_{\mathrm{SST}}$ variations for the period 1985-2016. 
(a)
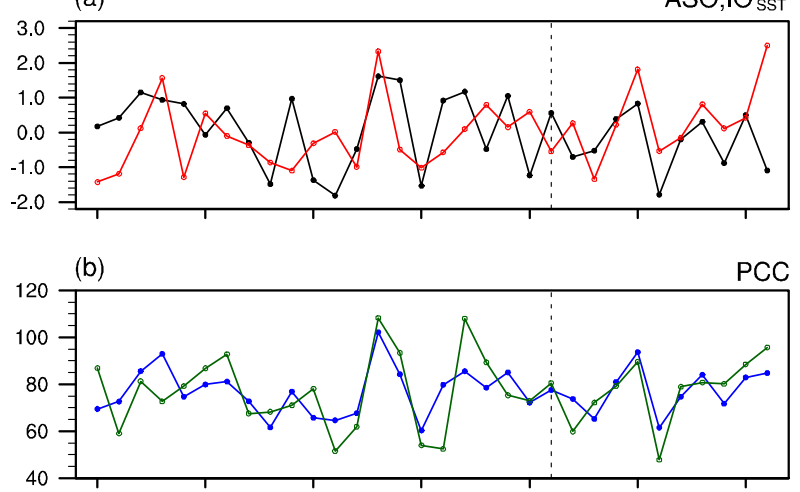

(c)

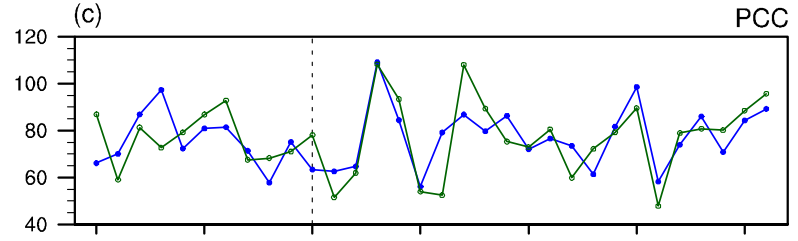

(d)

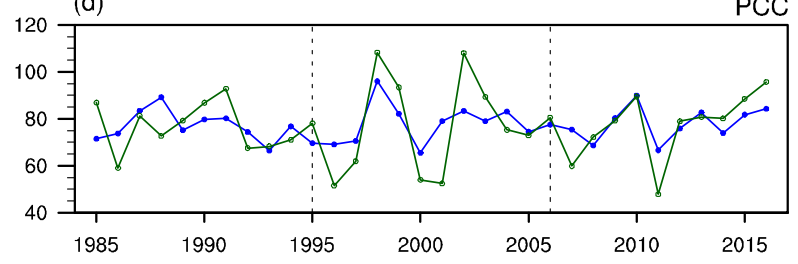

FIG. 9. (a) Standardized time series of February-March ASO (black line) and February-March $\mathrm{IO}_{\mathrm{SST}}$ (red line) for the period 1985-2016. (b) Observed April-May PCC (green line) and fitted April-May PCC variations (blue line) established by the linear regression model based on February-March ASO and IO SST $_{\text {dur- }}$ ing 1985-2016. The training period is 1985-2006 and the independent test period is 2007-16. (c) As in (b), but the training period is 1995-2016 and the independent test period is 1985-94. (d) As in (b), but the training periods are 1985-95 and 2006-16, and the independent test period is 1996-2005.

Figure 9 and Table 4 show that the fitted April-May PCCs are highly consistent with observed April-May PCC in different training period and test period schemes; that is, all correlation coefficients between fitted PCCs and observed PCC are significant and all anomaly sign consistency rates are above $60 \%$. Overall, this implies that the linear regression model has good stability and predictability. In addition, the correlation coefficients among observed PCC, ASO, $\mathrm{IO}_{\mathrm{SST}}$, and fitted PCC variations are also significant at the $95 \%$ confidence level based on the Monte Carlo test (not shown), which supports the conclusions based on the Student's $t$ test.

In 1998, China suffered from severe flooding that affected 223 million people and destroyed nearly 5 million houses. The direct economic losses reached 166600 million Yuan ( $£ 12.8$ billion), according to a report issued by the State Council of China published in the People's Daily on 26 August. In addition, the spring precipitation in the Yangtze River basin was abnormally high in 1998. The February-March ASO and IO $_{\text {SST }}$ are both strongly positive in 1998 (Fig. 9a). The fitted PCC is similar, with a large positive anomaly of $>100 \mathrm{~mm}$ in April-May 1998 (Fig. 9b).

\section{b. Building the linear regression model from simulations}

Further, we performed a transient experiment by CESM model to validate the relationships among PCC and ASO and $\mathrm{IO}_{\mathrm{SST}}$, and to test the stability of the established linear regression model. Significant correlations can be found between specified February-March ASO and CESM model simulated April-May PCC (Fig. 10a; $R=0.33$ ) and between CESM model simulated February-March $\mathrm{IO}_{\text {SST }}$ and CESM model simu-

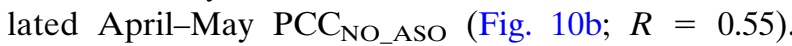
Figure 10c shows that the CESM model simulated April-May PCC (green line) variations are significantly correlated with the fitted PCC (blue line) during both the training period $(R=0.59$, significant at the $99 \%$ confidence level) and test period $(R=0.65$, significant at the $99 \%$ confidence level). The fitted PCC obtained by the linear regression model is based on specified February-March ASO and CESM model simulated February-March $\mathrm{IO}_{\text {SST. }}$. It illustrates that the lead-lag relationships among $\mathrm{ASO}, \mathrm{IO}_{\mathrm{SST}}$, and $\mathrm{PCC}$ can be found

TABLE 4. Correlation coefficients, RMSE of cross-validation tests, and anomaly sign consistency rate $P$ between observed and fitted April-May precipitation over central China (PCC).One asterisk indicates a correlation coefficient that is significant at the $90 \%$ level; two asterisks indicate a correlation coefficient that is significant the $95 \%$ level.

\begin{tabular}{lccc}
\hline \hline & Correlation coefficients & RMSE (mm) & $P(\%)$ \\
\hline Training period (1985-2006) & $0.64^{* *}$ & 13.96 & $68 \%$ \\
Test period (2007-16) & $0.80^{* *}$ & 15.80 & 12.37 \\
Training period (1995-2016) & $0.77 * *$ & 13.44 & $73 \%$ \\
Test period (1985-94) & $0.47^{*}$ & 11.54 & $70 \%$ \\
Training period (1985-95, 2006-16) & $0.56^{* *}$ & 16.82 & $73 \%$ \\
Test period (1996-2005) & $0.80^{* *}$ & $80 \%$ \\
\hline
\end{tabular}



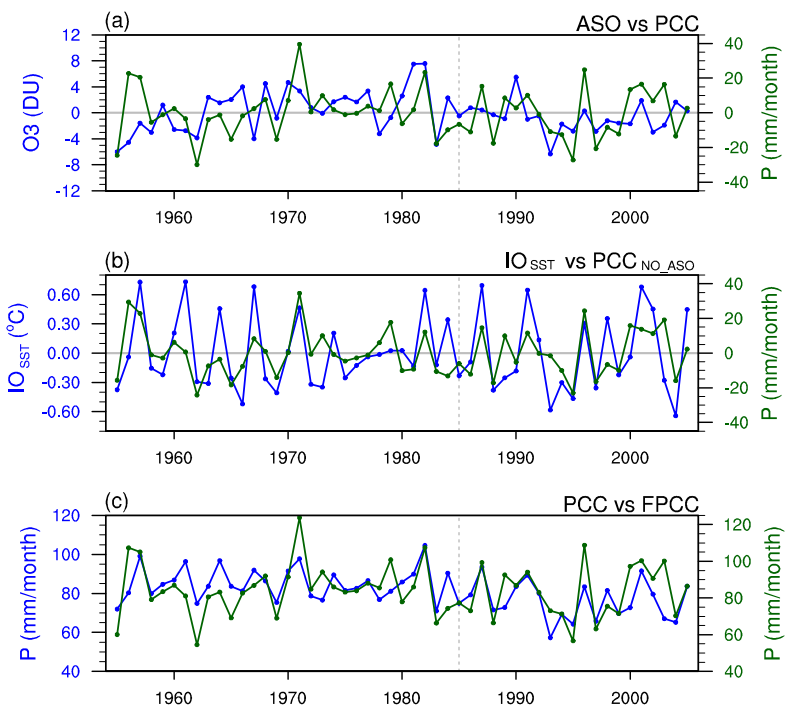

FIG. 10. (a) Specified February-March ASO (blue line) vs CESM-simulated April-May PCC (green line) variations during 1955-2005. (b) CESM-simulated February-March IO SST $_{\text {(blue }}$ line) vs CESM-simulated April-May $\mathrm{PCC}_{\mathrm{NO}}$ Aso (green line) variations. $\mathrm{PCC}_{\mathrm{NO}}$ Aso is obtained by removing the ASO signal from PCC. (c) CESM-simulated April-May PCC variations (green line) and fitted April-May PCC (blue line) established by the linear regression model based on specified February-March ASO and CESM-simulated February-March $\mathrm{IO}_{\text {SST. }}$. The training period is 1955-85, and the independent test period is 1986-2005.

not only in observations but also in the transient experiment and that the established linear regression model is stable.

\section{Conclusions}

This study constructs a linear regression model for AprilMay PCC applied to observational and reanalysis datasets. Two preceding factors are selected: the February-March ASO and the February-March IO $_{\text {SST. }}$. They imply a synergistic effect of Arctic and tropical signals on the midlatitude climate. This linear regression model not only reproduces the April-May PCC but also demonstrates strong robustness and reliability during the independent test period. The WACCM4 simulations also support the results from our statistical analysis of observations.

The February-March ASO changes significantly correlate with the spring rainfall variations over central China. A possible link from ASO to PCC is that the circulation anomalies over the North Pacific related to FebruaryMarch ASO changes may extend westward to central China, causing local circulation anomalies and leading to the April-May PCC anomalies. For another predictor, the February-March $\mathrm{IO}_{\mathrm{SST}}$ anomalies can persist to AprilMay, and April-May $\mathrm{IO}_{\mathrm{SST}}$ anomalies force a baroclinic structure over central China. For example, when the $\mathrm{IO}_{\mathrm{SST}}$ is anomalously warm, this forces an anomalously high pressure in the upper and middle troposphere over central China, but negative anomalies in the lower troposphere. This baroclinic structure, on one hand, strengthens the upwelling over central China, while on the other hand, it can also enhance water vapor transport from the South China Sea to central China. In addition, the $\mathrm{IO}_{\text {SST }}$ positive anomalies could make the upper-level jet stream shift northward. Thus, central China is situated over the right entrance region of the jet, with a corresponding tendency for upward motion and rain production. Under these conditions, central China is covered by cyclones, updrafts, and warm and wet air, resulting in more April-May precipitation, whereas anomalously cold $\mathrm{IO}_{\mathrm{SST}}$ has the opposite effect.

Acknowledgments. Funding for this work was provided by the National Natural Science Foundation of China (41790474, 41630421, and 41975047). We acknowledge ozone datasets from SWOOSH; precipitation from China Meteorological Administration, GPCC and GPCP; meteorological fields from NCEP2; and sea surface temperature from the Hadley Centre. We thank NCAR for providing the CESM model.

\section{REFERENCES}

Adler, R. F., and Coauthors, 2003: The version-2 Global Precipitation Climatology Project (GPCP) monthly precipitation analysis (1979-present). J. Hydrometeor., 4, 1147-1167, https://doi.org/ 10.1175/1525-7541(2003)004<1147:TVGPCP > 2.0.CO;2.

Calvo, N., L. M. Polvani, and S. Solomon, 2015: On the surface impact of Arctic stratospheric ozone extremes. Environ. Res. Lett., 10, 094003, https://doi.org/10.1088/1748-9326/10/9/094003.

Chang, C. P., Y. S. Zhang, and T. Li, 2000: Interannual and interdecadal variations of the East Asian summer monsoon and tropical Pacific SSTs. Part I: Roles of the subtropical ridge. J. Climate, 13, 4310-4325, https://doi.org/10.1175/15200442(2000)013<4310:IAIVOT>2.0.CO;2.

Chen, J. P., Z. P. Wen, R. G. Wu, Z. S. Chen, and P. Zhao, 2014: Interdecadal changes in the relationship between southern China winter-spring precipitation and ENSO. Climate Dyn., 43, 1327-1338, https://doi.org/10.1007/s00382-013-1947-x.

Chen, W., L. Wang, Y. K. Xue, and S. F. Sun, 2009: Variabilities of the spring river runoff system in East China and their relations to precipitation and sea surface temperature. Int. J. Climatol., 29, 1381-1394, https://doi.org/10.1002/joc. 1785.

Davis, S. M., and Coauthors, 2016: The Stratospheric Water and Ozone Satellite Homogenized (SWOOSH) database: A longterm database for climate studies. Earth Syst. Sci. Data, 8, 461490, https://doi.org/10.5194/essd-8-461-2016.

Ding, Y., 1994: Monsoons over China. Springer, 419 pp.

Feng, J., and J. P. Li, 2011: Influence of El Niño Modoki on spring rainfall over south China. J. Geophys. Res., 116, D13102, https://doi.org/10.1029/2010JD015160.

Feng, J. Q., L. J. Yu, and D. X. Hu, 2014: Influence of Indian Ocean subtropical dipole on spring rainfall over China. Int. J. Climatol., 34, 954-963, https://doi.org/10.1002/joc.3732. 
Folland, C. K., T. R. Karl, and K. Y. A. Vinnikov, 1990: Observed climate variations and change. Climate Change: The IPCC Scientific Assessment. J. T. Houghton, G. J. Jenkins, and J. J. Ephraums, Eds., Cambridge University Press, 195-238.

Froidevaux, L., and Coauthors, 2015: Global OZone Chemistry And Related trace gas Data records for the Stratosphere (GOZCARDS): Methodology and sample results with a focus on $\mathrm{HCl}, \mathrm{H}_{2} \mathrm{O}$, and $\mathrm{O}_{3}$. Atmos. Chem. Phys., 15, 10 471-10 07, https://doi.org/10.5194/acp-15-10471-2015.

Gemmer, M., S. Becker, and T. Jiang, 2004: Observed monthly precipitation trends in China 1951-2002. Theor. Appl. Climatol., 77, 39-45, https://doi.org/10.1007/s00704-003-0018-3.

Gong, D.-Y., and S.-W. Wang, 2000: Severe summer rainfall in China associated with enhanced global warming. Climate Res., 16, 51-59, https://doi.org/10.3354/cr016051.

— , and C.-H. Ho, 2002: Shift in the summer rainfall over the Yangtze River valley in the late 1970s. Geophys. Res. Lett., 29, 1436, https://doi.org/10.1029/2001GL014523.

Guo, Y., J. P. Li, and Y. Li, 2012: A time-scale decomposition approach to statistically downscale summer rainfall over north China. J. Climate, 25, 572-591, https://doi.org/10.1175/JCLID-11-00014.1.

Huang, R. H., L. T. Zhou, and W. Chen, 2003: The progresses of recent studies on the variabilities of the East Asian monsoon and their causes. Adv. Atmos. Sci., 20, 55-69, https://doi.org/ 10.1007/BF03342050.

Hurrell, J. W., 1996: Influence of variations in extratropical wintertime teleconnections on Northern Hemisphere temperature. Geophys. Res. Lett., 23, 665-668, https://doi.org/10.1029/96GL00459.

Ivy, D. J., S. Solomon, N. Calvo, and D. W. J. Thompson, 2017: Observed connections of Arctic stratospheric ozone extremes to Northern Hemisphere surface climate. Environ. Res. Lett., 12, 024004, https://doi.org/10.1088/1748-9326/aa57a4.

Jones, P. D., M. New, D. E. Parker, S. Martin, and I. G. Rigor, 1999: Surface air temperature and its changes over the past 150 years. Rev. Geophys., 37, 173-199, https://doi.org/10.1029/ 1999RG900002.

Kim, M.-K., I.-S. Kang, C.-K. Park, and K.-M. Kim, 2004: Superensemble prediction of regional precipitation over Korea. Int. J. Climatol., 24, 777-790, https://doi.org/10.1002/joc.1029.

Lau, K.-M., and M.-T. Li, 1984: The monsoon of East Asia and its global associations-A survey. Bull. Amer. Meteor. Soc., 65, 114-125, https://doi.org/10.1175/1520-0477(1984)065<0114: TMOEAA $>2.0 . \mathrm{CO} ; 2$.

Lean, J., G. Rottman, J. Harder, and G. Kopp, 2005: SORCE contributions to new understanding of global change and solar variability. Sol. Phys., 230, 27-53, https://doi.org/10.1007/ s11207-005-1527-2.

Li, X. F., J. P. Li, and Y. Li, 2015: Recent winter precipitation increase in the middle-lower Yangtze River valley since the late 1970s: A response to warming in the tropical Indian Ocean. J. Climate, 28, 3857-3879, https://doi.org/10.1175/ JCLI-D-14-00701.1.

Liu, S., and A. Duan, 2017: Impacts of the leading modes of tropical Indian Ocean sea surface temperature anomaly on subseasonal evolution of the circulation and rainfall over East Asia during boreal spring and summer. J. Meteor. Res., 31, 171-186, https://doi.org/10.1007/s13351-016-6093-z.

Liu, X. D., and Y. Wang, 2011: Contrasting impacts of spring thermal conditions over Tibetan Plateau on late-spring to early-summer precipitation in southeast China. Atmos. Sci. Lett., 12, 309-315, https://doi.org/10.1002/asl.343.
Manton, M. J., and Coauthors, 2001: Trends in extreme daily rainfall and temperature in Southeast Asia and the South Pacific: 19611998. Int. J. Climatol., 21, 269-284, https://doi.org/10.1002/joc.610.

Marsh, D. R., M. J. Mills, D. E. Kinnison, J.-F. Lamarque, N. Calvo, and L. M. Polvani, 2013: Climate change from 1850 to 2005 simulated in CESM1(WACCM). J. Climate, 26, 73727391, https://doi.org/10.1175/JCLI-D-12-00558.1.

Qiu, Y., W. J. Cai, X. G. Guo, and A. J. Pan, 2009: Dynamics of late spring rainfall reduction in recent decades over southeastern China. J. Climate, 22, 2240-2247, https://doi.org/ 10.1175/2008JCLI2809.1.

Rayner, N. A., D. E. Parker, E. B. Horton, C. K. Folland, L. V. Alexander, and D. P. Rowell, 2003: Global analyses of sea surface temperature, sea ice, and night marine air temperature since the late nineteenth century. J. Geophys. Res., 108, 4407, https://doi.org/10.1029/2002JD002670.

Schneider, U., T. Fuchs, A. Meyer-Christoffer, and B. Rudolf, 2008: Global precipitation analysis products of the GPCC. Global Precipitation Climatology Centre, 12 pp.

Smith, K. L., and L. M. Polvani, 2014: The surface impacts of Arctic stratospheric ozone anomalies. Environ. Res. Lett., 9, 074015 , https://doi.org/10.1088/1748-9326/9/7/074015.

Sun, C. H., and S. Yang, 2012: Persistent severe drought in southern China during winter-spring 2011: Large-scale circulation patterns and possible impacting factors. J. Geophys. Res., 117, D10112, https://doi.org/10.1029/2012JD017500.

Wang, B., R. G. Wu, and X. H. Fu, 2000: Pacific-East Asian teleconnection: How does ENSO affect East Asian climate? J. Climate, 13, 1517-1536, https://doi.org/10.1175/15200442(2000)013<1517:PEATHD>2.0.CO;2.

— G. Wu, and T. Li, 2003: Atmosphere-warm ocean interaction and its impacts on Asian-Australian monsoon variation. J. Climate, 16, 1195-1211, https://doi.org/10.1175/15200442(2003)16<1195:AOIAII >2.0.CO;2.

Wang, H. J., F. Xue, and G. Q. Zhou, 2002: The spring monsoon in South China and its relationship to large-scale circulation features. $A d v$. Atmos. Sci., 19, 651-664, https://doi.org/10.1007/s00376-002-0005-0.

WMO, 2003: Scientific Assessment of Ozone Depletion: 2002. Global Ozone Research and Monitoring Project Rep. 47, World Meteorological Organization, $498 \mathrm{pp}$.

Wu, R. G., and B. Kirtman, 2007: Observed relationship of spring and summer East Asian rainfall with winter and spring Eurasian snow. J. Climate, 20, 1285-1304, https:// doi.org/10.1175/JCLI4068.1.

— Z. Z. Hu, and B. Kirtman, 2003: Evolution of ENSO-related rainfall anomalies in East Asia. J. Climate, 16, 3742-3758, https:// doi.org/10.1175/1520-0442(2003)016<3742:EOERAI >2.0.CO;2.

Xie, F., and Coauthors, 2016: A connection from Arctic stratospheric ozone to El Niño-Southern Oscillation. Environ. Res. Lett., 11, 124026, https://doi.org/10.1088/1748-9326/11/12/124026.

_ J. K. Zhang, W. J. Sang, Y. Li, Y. L. Qi, C. Sun, Y. Li, and J. C. Shu, 2017a: Delayed effect of Arctic stratospheric ozone on tropical rainfall. Atmos. Sci. Lett., 18, 409-416, https://doi.org/10.1002/asl.783.

— , and Coauthors, 2017b: Variations in North Pacific sea surface temperature caused by Arctic stratospheric ozone anomalies. Environ. Res. Lett., 12, 114023, https://doi.org/10.1088/1748-9326/aa9005. -, and Coauthors, 2018: An advanced impact of Arctic stratospheric ozone changes on spring precipitation in China. Climate Dyn., 51, 4029-4041, https://doi.org/10.1007/s00382-018-4402-1.

Xie, S.-P., K. M. Hu, J. Hafner, H. Tokinaga, Y. Du, G. Huang, and T. Sampe, 2009: Indian Ocean capacitor effect on Indo-western Pacific climate during the summer following El Niño. J. Climate, 22, 730-747, https://doi.org/10.1175/2008JCLI2544.1. 
Xin, X. G., R. C. Yu, T. J. Zhou, and B. Wang, 2006: Drought in late spring of South China in recent decades. J. Climate, 19, 3197 3206, https://doi.org/10.1175/JCLI3794.1.

Yang, F. L., and K. M. Lau, 2004: Trend and variability of China precipitation in spring and summer: Linkage to sea-surface temperatures. Int. J. Climatol., 24, 1625-1644, https://doi.org/ 10.1002/joc.1094.

Zhang, R. H., and A. Sumi, 2002: Moisture circulation over East Asia during El Niño episode in northern winter, spring and autumn. J. Meteor. Soc. Japan, 80, 213-227, https://doi.org/ 10.2151/jmsj.80.213.

- _ - and M. Kimoto, 1999: A diagnostic study of the impact of El Niño on the precipitation in China. Adv. Atmos. Sci., 16, 229-241, https://doi.org/10.1007/BF02973084.
Zhu, C. W., X. J. Zhou, Z. Ping, L. X. Chen, and J. H. He, 2011: Onset of East Asian subtropical summer monsoon and rainy season in China. Sci. China Earth Sci., 54, 1845-1853, https:// doi.org/10.1007/s11430-011-4284-0.

Zorita, E., and H. von Storch, 1999: The analog method as a simple statistical downscaling technique: Comparison with more complicated methods. J. Climate, 12, 24742489, https://doi.org/10.1175/1520-0442(1999)012<2474: TAMAAS $>2.0 . \mathrm{CO} ; 2$.

Zuo, Z. Y., R. H. Zhang, B. Y. Wu, and X. Y. Rong, 2012: Decadal variability in springtime snow over Eurasia: Relation with circulation and possible influence on springtime rainfall over China. Int. J. Climatol., 32, 1336-1345, https://doi.org/10.1002/ joc. 2355 . 